Effect of the CYP2D6*10 Genotype on Tolterodine Pharmacokinetics.

Masayo Oishi, Koji Chiba, Bimal Malhotra, and Toshio Suwa

Clinical pharmacology, Clinical Research, Tokyo Laboratories, Pfizer Japan Inc., Tokyo, Japan (M.O.); Department of Drug Development Science \& Clinical Evaluation, Keio University of Pharmacy, Tokyo, Japan (M.O., K.C., T.S.); and Clinical pharmacology, Pfizer Inc, New York, NY, USA (B.M.) 
DMD \#33407

Running title: Effect of the CYP2D6*10 on tolterodine pharmacokinetics

\section{Corresponding author: Masayo Oishi}

Address: $\quad 3-22-7$, Yoyogi, Shibuya-ku, Tokyo 151-8589 Japan

Tel: $\quad+\quad+81-3-5309-7420$

Fax: $\quad+81-3-5309-9841$

e-mail: $\quad$ masayo.oishi@pfizer.com

Number of text pages: $\quad 28$

Number of references: $\quad 22$

Number of figures: $\quad 5$

Number of tables: $\quad 3$

Number of words in the Abstract: 248

Number of words in the Introduction: 747

Number of words in the Discussion: 1074

\section{List of nonstandard abbreviations:}

5-HM, 5-hydroxymethyl metabolite of tolterodine 


\begin{abstract}
This study was conducted to investigate the effect of the reduced function allele CYP2D6*10 which can cause intermediate metabolizer (IM) on tolterodine pharmacokinetics. Tolterodine is mainly metabolized to active 5-hydroxymethyl metabolite (5-HM) by CYP2D6 and 5-HM is also metabolized by CYP2D6. Asian and Caucasian healthy volunteers $(n=108)$ received once daily multiple doses of tolterodine and the serum concentrations of tolterodine and 5-HM were measured. All subjects were genotyped for CYP2D6. Tolterodine exposures (AUC) increased in order of $C Y P 2 D 6 * 1 / * 1$ (extensive metabolizer, EM) < CYP2D6*1/*10<CYP2D6*10/*10< $C Y P 2 D 6 * 5 / * 10$. It was expected that the order of 5-HM exposure would be reversed. However, 5-HM AUC increased in the same order as tolterodine. This phenomenon was explained by considering the CYP2D6 mediation of both production and elimination of 5-HM. The exposures of tolterodine and 5-HM in CYP2D6*10/*10 were statistically higher than $C Y P 2 D 6^{*} 1 / * 1$ (3- and 1.5 -fold, respectively). In $C Y P 2 D 6 * 4 / 44$ (poor metabolizer, PM), 5-HM was not produced and exposure of tolterodine was 20-fold higher than $C Y P 2 D 6 * 1 / * 1$. With consideration for higher protein binding of tolterodine than 5-HM, the exposure as sum of unbound fraction of tolterodine and 5-HM (active moiety) in $C Y P 2 D 6 * 10 / * 10$ was 1.8 -fold higher than $C Y P 2 D 6 * 1 / * 1$ and was also higher than $C Y P 2 D 6 * 4 / * 4$. Simulation using the values of EM and PM demonstrated that the maximum possible active moiety exposure was around the observed values of $C Y P 2 D 6 * 5 / * 10$ which was 1.9 -fold higher than $C Y P 2 D 6 * 1 / * 1$. This is the first report to provide the example of which IM shows higher exposure to pharmacological active moiety than EM and PM.
\end{abstract}




\section{Introduction}

Tolterodine, $(R)-N, N$-diisopropyl-3-(2-hydroxy-5-methylphenyl)-3-phenylpropanamine, is an antimuscarinic drug for the treatment of overactive bladder. In humans, tolterodine is mainly eliminated by metabolism, with slight excretion into urine (Postlind et al., 1998). There are two different oxidative metabolic pathways, hydroxylation and $N$-dealkylation, that have been identified in humans (Postlind et al., 1998). Hydroxylation to the pharmacologically active 5-hydroxymethyl metabolite (5-HM) is the predominant metabolic pathway which is catalysed by cytochrome P450 (CYP) 2D6, while the minor $N$-dealkylation pathway is mediated by CYP3A (Postlind et al., 1998). 5-HM itself is metabolized by two major pathways of CYP2D6 and CYP3A4 and it is also renally excreted (Malhotra et al., 2008). Preclinical studies have demonstrated that 5-HM is pharmacologically equipotent compared with tolterodine in vitro, and has similar functional bladder selectivity in vivo (Nilvebrant, 2000).

It is well established that CYP2D6 is subject to genetic polymorphism (http://www.cypalleles.ki.se/cyp2d6.htm). Over 70 CYP2D6 allelic variants have been discovered thus far (Zhou, 2009). They are classified as functional, non-functional and reduced functional groups (Bradford, 2002). CYP2D6 allele frequency is known to vary among ethnic groups. Generally, for Europeans, the functional group of alleles are predominant with the presence of non-functional alleles mainly as $C Y P 2 D 6 * 4$. On the other hand, Asians and their close descendants have a low frequency of homozygous of non-functional alleles whereas they have a high frequency of the reduced function allele, CYP2D6*10 (Bradford, 2002; Ozawa et al., 2004; Ingelman-Sundberg, 2005; Bernard et al., 2006).

In extensive metabolizers (EM) of CYP2D6, the mean systemic clearance of tolterodine was found to be $44 \mathrm{~L} / \mathrm{h}$ with a half-life of 2-3 h (Brynne et al., 1998). In contrast, poor metabolizers $(\mathrm{PM})$ have 5-times lower clearance $(9 \mathrm{~L} / \mathrm{h})$ with a mean half-life of $9 \mathrm{~h}$. The levels of 5-HM are similar to those of tolterodine in EM and not quantifiable in PM 
(Brynne et al., 1998). Despite differences in tolterodine pharmacokinetics between EM and PM, exposures to active moiety, the sum of unbound tolterodine and 5-HM, are comparable between EM and PM (Larsson et al., 1999) due to the 10-fold lower unbound fraction for tolterodine (3.7\%) relative to 5-HM (36\%) in serum (Pahlman and Gozzi, 1999). The clinical antimuscarinic effects of tolterodine are similar in CYP2D6 EMs and PMs (Van Kerrebroeck et al., 2001). Based on the comparable exposure of active moiety and the clinical effects across EMs and PMs, the dose adjustment has not been necessary between EMs and PMs (Clemett and Jarvis, 2001).

The effect of complete deficiency of CYP2D6 activity in PM on the pharmacokinetics of tolterodine has been investigated (Brynne et al., 1998). However, there has been no investigation about the effect of reduced function alleles, such as $C Y P 2 D 6 * 10$ which can be the cause of intermediate metabolizer (IM), on the pharmacokinetics of tolterodine and 5-HM. To our knowledge, this is the first report of clinical study to demonstrate tolterodine and 5-HM exposures with CYP2D6 polymorphism including CYP2D6 *10 allele.

In IM of CYP2D6, it is expected that tolterodine exposure increases due to reduced enzyme activity. On the other hand, it is complicated to estimate the exposure of 5-HM. The active metabolite 5-HM is biotransformed from tolterodine by CYP2D6 and 5-HM itself is also metabolized by CYP2D6. When the activity of CYP2D6 reduces, 5-HM exposure may decrease due to decreasing the amount of 5-HM biotransformed from tolterodine, whereas exposure of 5-HM may increase due to reduction of clearance for 5-HM. Therefore, there is a possibility that IM has the highest exposure of 5-HM and it can cause higher active moiety exposure in IM than EM and PM.

The aim of the present study was to investigate the effect of the CYP2D6 genotypes, especially for $C Y P 2 D 6 * 10$ allele on the pharmacokinetics of tolterodine and 5-HM, with consideration of the opposite directional effects of reduced CYP2D6 enzyme activity, i.e. enhancement and reduction of 5-HM exposure. We also investigated the 
effect of CYP2D6 *10 allele on active moiety exposure, the sum of unbound tolterodine and 5-HM, among EMs, IMs and PMs.

In addition, to investigate the magnitude of reduction in CYP2D6 intrinsic clearance in IMs, we estimated intrinsic clearances of CYP2D6 for tolterodine and 5-HM in each genotype from the data of the present study. Furthermore, to understand and describe the trend of change in exposures of 5-HM and active moiety by differences of CYP2D6 enzyme activity among various genotypes and to predict the maximum exposure, we simulated the exposures of tolterodine, 5-HM and active moiety with changing CYP2D6 intrinsic clearance and compared the simulated results with the observed values. 


\section{Materials and Methods}

\section{$\underline{\text { Subjects }}$}

A total of 72 Asian (Japanese and Koreans, 24 male and 48 female) and 36 Caucasian (12 male and 24 female) subjects received tolterodine administration in this study. Concomitant use of any other medication was not permitted. The study was performed in accordance with the latest revisions to the Declaration of Helsinki, ethical approval having been obtained from the local Institutional Review Board of Health and Regulatory Affairs Authority. All volunteers gave their written informed consent prior to commencement of the study.

\section{Study design}

This was a randomized, multiple-dose study in healthy Asian and Caucasian subjects. The doses were administered as prolonged release capsules (PR). There were three dose groups of 2-, 4-, and 6-mg tolterodine L-tartrate, each group including 36 subjects. Each subject received daily single doses of tolterodine PR for 5 consecutive days.

\section{CYP2D6 genotyping}

Genotyping was conducted via DNA purification from whole blood prior to the first dosing and DNA was extracted using Gentra 'PureGene' kit method. The presence of $C Y P 2 D 6 * 3, C Y P 2 D 6 * 4, C Y P 2 D 6 * 5$ and $C Y P 2 D 6 * 10$ was tested for each subject. They were determined using multiplex polymerase chain reaction $(C Y P 2 D 6 * 3$ and $* 4)$, long-range polymerase chain reaction $(C Y P 2 D 6 * 5)$ and allele specific amplification (CYP2D6*10), respectively (PPGx, Cambridge, UK). If no variations were detected on an allele, it was defaulted to a wild type $\left(C Y P 2 D 6^{*} 1\right)$ assignment. Following genotypes were found in the subjects of the present study: CYP $2 D 6 * 1 / * 1, C Y P 2 D 6 * 1 / * 10$, $C Y P 2 D 6 * 1 / * 4, C Y P 2 D 6 * 1 / * 5, C Y P 2 D 6 * 10 / * 10, C Y P 2 D 6 * 5 / * 10$ and $C Y P 2 D 6 * 4 / * 4$. The expected phenotypes for each genotype were defined as follows: EM 
$\left(C Y P 2 D 6^{*} 1 / * 1\right), \mathrm{IM}(C Y P 2 D 6 * 1 / * 10, C Y P 2 D 6 * 1 / * 4, C Y P 2 D 6 * 1 / * 5, C Y P 2 D 6 * 10 / * 10$ and $C Y P 2 D 6 * 5 / * 10)$ and PM $(C Y P 2 D 6 * 4 / 4)$.

\section{Pharmacokinetic sampling}

Venous blood samples for determination of tolterodine and 5-HM were drawn. Steady state sampling was carried out at $0,0.5,1,2,3,4,6,9,12,18$ and 24 hours after the last administration. The blood samples $(7 \mathrm{~mL})$ were collected at each point in evacuated collection tubes without additives. The blood samples were allowed to coagulate for 45 minutes to 1 hour, after which serum was separated by centrifugation $(1,000 \mathrm{x} \mathrm{g}$ for 10 minutes) at room temperature. The serum samples were stored frozen at $-20^{\circ} \mathrm{C}$ until analyzed.

A blood sample in connection with the pre-dose sample on the last dosing day was taken for determination of $\alpha_{1}$-acid glycoprotein (AGP).

\section{$\underline{\text { Analytical methods }}$}

Serum samples were assayed for tolterodine and 5-HM using a validated high-performance liquid chromatography with tandem mass spectrometry (LC/MS/MS) method (AAI Deutschland GmbH \& Co. KG, Germany). Stable isotope analogues of tolterodine $((R)-\quad N, N$ - diisopropyl- 3-(2-hydroxy-5-methylphenyl)-3-(pentadeuterophenyl) propanamine L-tartrate) and 5-HM (N,N- diisopropyl3-(2-hydroxy-5-hydroxymethylphenyl)-3-(pentadeutero-phenyl) propanamine mandelate) were used as the internal standards, respectively. The compounds were separated from the serum by solid phase extraction using octadecyl (C18) columns. The resulting extracts were analyzed by LC/MS/MS using Zorbax SB-CN column, mobile phase composed of $60 \%$ ammonium acetate $(10 \mathrm{mM}), 30 \%$ methanol, $10 \%$ acetonitrile and $0.1 \%$ formic acid. The calibration standards for serum concentration assay were linear over the range of $0.1-100 \mathrm{ng} / \mathrm{mL}$. The lower limit of quantitation for both 
tolterodine and 5-HM was $0.1 \mathrm{ng} / \mathrm{mL}$. Assay accuracy for tolterodine and 5-HM was 0.2\%-3.3\% and -3.5\%-0.9\%. Assay precision for tolterodine and 5-HM was 4.5\%-7.4\% and $4.6 \%-6.9 \%$, respectively.

\section{$\underline{\text { Pharmacokinetic analysis }}$}

Pharmacokinetic parameters after multiple dosing were calculated based on serum concentrations of tolterodine and 5-HM. The calculations were performed by non-compartmental analysis using the Kinetica software (version 3.1; InnaPhase, PA, USA). The maximum serum concentration ( $\mathrm{Cmax}$ ) and area under the concentration time curve from 0 to $24 \mathrm{~h}$ after the dose $\left(\mathrm{AUC}_{0-24}\right)$ after multiple dosing were dose normalized to $4 \mathrm{mg}$ for the comparison among genotypes because linear pharmacokinetics of tolterodine was confirmed up to $8 \mathrm{mg}$ (Clemett and Jarvis, 2001).

Serum concentrations for the active moiety were calculated using serum concentration data for tolterodine and 5-HM, and individual AGP concentrations. The fraction unbound (fu) was calculated as follows (Pahlman and Gozzi, 1999):

$$
\begin{aligned}
& \mathrm{fu}_{\text {tolterodine }}=1 /(1+(2100 \times \mathrm{AGP}(\mathrm{g} / \mathrm{L}) / 42)) \\
& \mathrm{fu}_{5-\mathrm{HM}}=1 /(1+(130 \times \mathrm{AGP}(\mathrm{g} / \mathrm{L}) / 42))
\end{aligned}
$$

where $\mathrm{fu}_{\text {tolterodine }}$ and $\mathrm{fu}_{5-\mathrm{HM}}$ are unbound fraction of tolterodine and 5-HM, respectively.

The concentration of the active moiety $=\left(\mathrm{fu}_{\text {tolterodine }} \mathrm{x}\right.$ serum concentration of tolterodine $)+\left(\mathrm{fu}_{5-\mathrm{HM}} \mathrm{x}\right.$ serum concentration of 5-HM).

For the calculation of active moiety concentration, serum concentrations of tolterodine and 5-HM were converted to molar concentrations (nM) using the molecular weights of tolterodine (325.5) and 5-HM (341.5). 
Estimation of intrinsic clearances of CYP2D6 for tolterodine and 5-HM

The intrinsic clearances of CYP2D6 for tolterodine and 5-HM, and the amount of tolterodine biotranformed to 5-HM were estimated by the following steps:

(1) Estimation of intrinsic clearance of CYP2D6 for tolterodine and the amount of tolterodine biotransformed to 5-HM in each CYP2D6 genotype

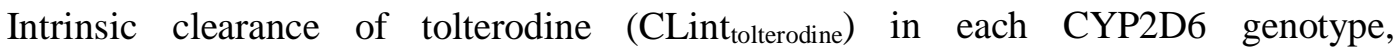
CYP2D6*1/*1, CYP2D6*1/*10, CYP2D6*1/*4 or CYP2D6*1/*5, CYP2D6*10/*10, $C Y P 2 D 6 * 5 / * 10$ and $C Y P 2 D 6 * 4 / * 4$, was estimated from the individual dose-normalized tolterodine $\mathrm{AUC}_{0-24}$ and individual fut $\mathrm{u}_{\text {tolterodine }}$ in the present study. The estimation was based on parallel tube model with assumption of ignorable renal clearance due to low urinary excretion ( $<3 \%$ (Brynne et al., 1998)) and fraction absorbed (fa) $\mathrm{x}$ intestinal availability (fg) equaled 1 . The fa $\mathrm{x}$ fg for tolterodine was assumed to be almost 1 because it was reported that bioavailability of tolterodine in PM was 0.91 (Brynne et al., 1998; Van Kerrebroeck et al., 2001). Parallel tube model was used for the estimation because the mean of futtolterodine $\mathrm{x}$ intrinsic clearance of CYP2D6 for tolterodine (CLint ${ }_{C Y P 2 D 6, t o l t e r o d i n e)}$ in $C Y P 2 D 6 * 1 / * 1$ was estimated as $157 \mathrm{~L} / \mathrm{h}$, which was higher than hepatic blood flow rate (Qh: 91.8 L/h (Kato et al., 2003)) (Ito and Houston, 2004). The median CLint tolterodine $_{\text {in }} 2$ subjects of $C Y P 2 D 6 * 4 / * 4$ in the present study was used as the CLint of tolterodine by the metabolic pathway other than CYP2D6

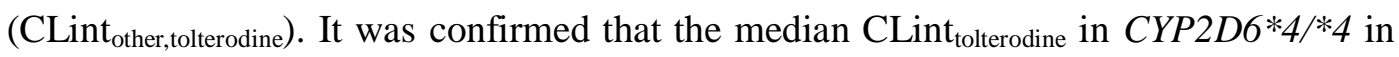
the present study $(436 \mathrm{~L} / \mathrm{h})$ was consist with the estimation $(443 \mathrm{~L} / \mathrm{h})$ from the total clearance in PM after intravenous infusion of tolterodine (Brynne et al., 1998).

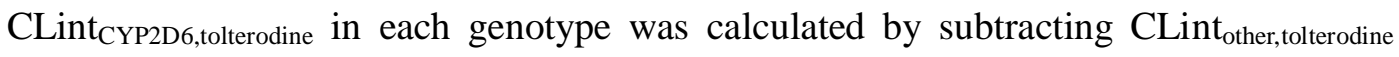

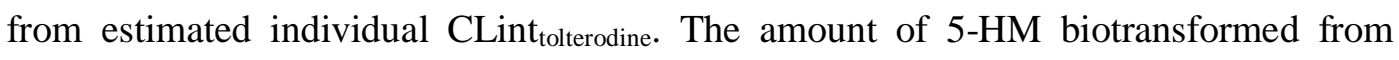

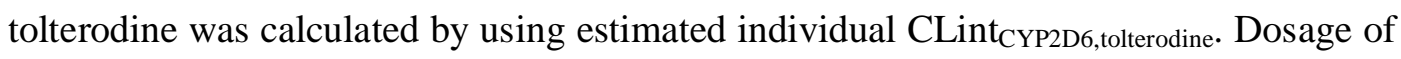


tolterodine was set at $2.74 \mathrm{mg}$ as tolterodine, which was correspondent to $4 \mathrm{mg}$ of tolterodine tartrate. The equations are shown in Appendix 1.

\section{(2) Estimation of intrinsic clearance of CYP2D6 for 5-HM in each CYP2D6 genotype}

With the estimated amount of 5-HM biotransformed from tolterodine calculated above, intrinsic clearance for 5-HM (CLint $\left.{ }_{\mathrm{CYP} 2 \mathrm{D} 6,5-\mathrm{HM}}\right)$ in each CYP2D6 genotype was estimated from individual dose-normalized 5-HM $\mathrm{AUC}_{0-24}$, individual $\mathrm{fu}_{5-\mathrm{HM}}$ in the present study, reported renal clearance of 5-HM (Malhotra et al., 2008) and CLint of 5-HM by the metabolic pathway other than CYP2D6 (CLint $\left.{ }_{\text {other,5-HM }}\right)$. The equations are shown in Appendix 2. Due to no data was available to calculate CLint $_{\text {other,5-HM }}$ in the

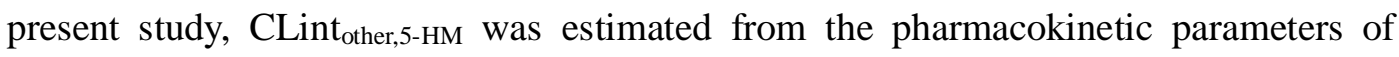
5-HM after intravenous infusion of 5-HM in EM and after oral administration of fesoterodine, which was a compound of esterified 5-HM, in EM and PM (http://www.emea.europa.eu/humandocs/Humans/EPAR/toviaz/toviaz.htm).

Simulation of the exposures of unbound tolterodine, 5-HM and active moiety with changing CLint ${ }_{\text {CYP2D6 }}$

Using the mean of estimated intrinsic clearances for tolterodine and for 5-HM in $C Y P 2 D 6 * 1 / * 1$ and $C Y P 2 D 6^{*} 4 / * 4$, the changes of AUCs of unbound tolterodine and

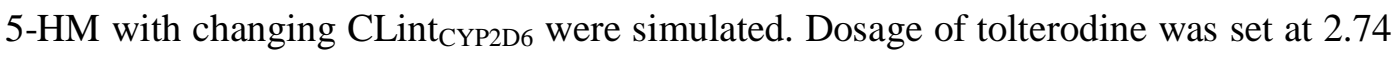
$\mathrm{mg}$ as tolterodine, which was correspondent to $4 \mathrm{mg}$ of tolterodine tartrate. The mean $\mathrm{fu}_{\text {tolterodine }}$ and fu $\mathrm{fu}_{5-\mathrm{HM}}$, which were 0.037 and 0.36 (Pahlman and Gozzi, 1999), and renal clearance of 5-HM (Malhotra et al., 2008) were used in this simulation. The reduction rate of CLint $\mathrm{CYP2D6}_{\text {was }}$ changed from no reduction $(0 \%, \mathrm{EM})$ to $100 \%$ reduction equaled to the condition in PM. Active moiety exposure was calculated as the sum of AUCs of unbound tolterodine and 5-HM. Details of the simulation are shown in Appendix 3. 
DMD \#33407

Statistical analysis

Statistical analysis for dose normalized $\mathrm{Cmax}$ and $\mathrm{AUC}_{0-24}$ of tolterodine, 5-HM and active moiety among genotypes was performed by one-way analysis of variance (ANOVA) and Bonferroni post hoc test by using SAS (version 8.02, SAS Institute Inc., NC, USA). CYP $2 D 6 * 5 / * 10$ and $C Y P 2 D 6 * 4 / * 4$ were not included in the ANOVA because only 2 subjects were classified as each genotype. Differences were considered to be statistically significant when P values were less than 0.05. Additionally, simulation of the change of exposures was conducted using SAS. 


\section{Results}

\section{Genotyping}

The allele frequencies of $C Y P 2 D 6 * 10$ in Asian and Caucasian subjects were $40 \%$ and $1.4 \%$, respectively. The allele frequency of $C Y P 2 D 6 * 5$ was $5.6 \%$ in Asians and $1.4 \%$ in Caucasians. There were no Asian subjects who had CYP2D6*4 allele but the allele frequency of $C Y P 2 D 6 * 4$ in Caucasians was $16.7 \%$. Demographics of subjects in each genotype are provided in Table 1.

\section{Pharmacokinetics}

The dose-normalized $\mathrm{Cmax}$ and $\mathrm{AUC}_{0-24}$ of tolterodine, 5-HM and active moiety after multiple dosing are summarized in Table 2, and are plotted in Figure 1, Figure 2 and Figure 3, respectively.

The mean values of dose-normalized $\mathrm{Cmax}$ and $\mathrm{AUC}_{0-24}$ of tolterodine in $C Y P 2 D 6 * 1 / * 10$ were similar to $C Y P 2 D 6^{*} 1 / * 1$, whereas those of $C Y P 2 D 6^{*} 1 / * 4$ or $C Y P 2 D 6 * 1 / * 5$ were approximately 1.9 - and 2-fold higher than $C Y P 2 D 6 * 1 / * 1$ (Table 2).

Both Cmax and $\mathrm{AUC}_{0-24}$ in $C Y P 2 D 6 * 10 / 10$ were significantly higher than CYP2D6*1/*1 and CYP2D6*1/*10 (Figure 1). They were approximately 2.6- and 3-fold higher than $C Y P 2 D 6^{*} 1 / * 1$, respectively. The Cmax and $\mathrm{AUC}_{0-24}$ values of 2 subjects of $C Y P 2 D 6 * 5 / * 10$ were higher than the mean value of $C Y P 2 D 6 * 10 / * 10$. The individual Cmax and $\mathrm{AUC}_{0-24}$ values of $C Y P 2 D 6 * 4 / * 4$ were approximately 10 - and 20 -fold higher than the mean of $C Y P 2 D 6^{*} 1 / * 1$, respectively. The values of $C Y P 2 D 6^{*} 5 / * 10$ and $C Y P 2 D 6 * 4 / 4$ were not included in the $95 \%$ confidence interval $(95 \% \mathrm{CI})$ of CYP2D6*10/*10 (Table 2).

The metabolite, 5-HM was unquantifiable in the subjects of $C Y P 2 D 6 * 4 / 4$. In other genotypes, Cmax values were distributed within the same range (Figure 2). The mean values of $\mathrm{AUC}_{0-24}$ tended to increase in the following order: $C Y P 2 D 6 * 1 / * 1$, 
$C Y P 2 D 6 * 1 / * 10, \quad C Y P 2 D 6 * 1 / * 4 \quad$ or $\quad C Y P 2 D 6 * 1 / * 5, \quad C Y P 2 D 6 * 10 / * 10 \quad$ and CYP2D6*5/*10 (Table 2). The mean value of $C Y P 2 D 6 * 1 / * 10$ was similar to $C Y P 2 D 6 * 1 / * 1$. The mean $\mathrm{AUC}_{0-24}$ values in $C Y P 2 D 6 * 1 / * 4$ or $C Y P 2 D 6 * 1 / * 5$ and $C Y P 2 D 6 * 10 / * 10$ were 1.2 - and 1.5 -fold higher than the value of $C Y P 2 D 6 * 1 / * 1$, respectively. The difference between $C Y P 2 D 6 * 1 / * 1$ and $C Y P 2 D 6 * 10 / * 10$ was statistically significant. The individual values of $C Y P 2 D 6 * 5 / * 10$ were similar to the mean of $C Y P 2 D 6 * 10 / * 10$ and they were not included in the $95 \% \mathrm{CI}$ of $C Y P 2 D 6 * 1 / * 1$ (Table 2).

As active moiety, the mean values of $\mathrm{Cmax}$ and $\mathrm{AUC}_{0-24}$ tended to increase in the following order: $C Y P 2 D 6 * 1 / * 1, \quad C Y P 2 D 6 * 1 / * 10, C Y P 2 D 6 * 1 / * 4$ or $C Y P 2 D 6 * 1 / * 5$, $C Y P 2 D 6 * 10 / * 10$ and $C Y P 2 D 6 * 5 / * 10$ (Table 2). The mean Cmax value in CYP2D6*10/*10 was 1.4 -fold higher than $C Y P 2 D 6^{*} 1 / * 1$ and it was statistically significant (Figure 3). The mean $\mathrm{AUC}_{0-24}$ values in $C Y P 2 D 6 * 1 / * 10$ and $C Y P 2 D 6 * 1 / * 4$ or $C Y P 2 D 6^{*} 1 / * 5$ were 1.3 - and 1.5 -fold higher than the value of $C Y P 2 D 6^{*} 1 / * 1$, respectively, and these differences were statistically significant. The $\mathrm{AUC}_{0-24}$ in $C Y P 2 D 6 * 10 / * 10$ was 1.8 -fold higher than $C Y P 2 D 6^{*} 1 / * 1$ and was significantly higher than $C Y P 2 D 6 * 1 / * 1$ and $C Y P 2 D 6 * 1 / * 10$. The individual values of $C Y P 2 D 6 * 5 / * 10$ were included in the in the $95 \% \mathrm{CI}$ of $C Y P 2 D 6 * 10 / * 10$ but were higher than that $C Y P 2 D 6 * 1 / * 1$. The individual exposures in $C Y P 2 D 6 * 4 / * 4$ were distributed between the mean of $C Y P 2 D 6 * 1 / * 1$ and $C Y P 2 D 6^{*} 1 / * 10$ and they were not included in the $95 \% \mathrm{CI}$ of $C Y P 2 D 6 * 1 / * 1$.

Estimation of intrinsic clearances of CYP2D6 for tolterodine and 5-HM metabolisms

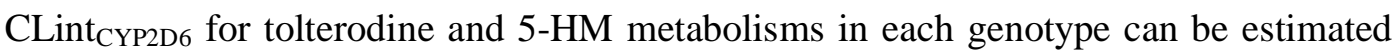
from the AUC values using liver model. The estimated CLint ${ }_{\text {CYP2D6 }}$ for tolterodine and 5-HM metabolisms in each genotype are shown in Table 3.

CLint $_{\mathrm{CYP} 2 \mathrm{D} 6, \text { tolterodine }}$ and CLint ${ }_{\mathrm{CYP} 2 \mathrm{D} 6,5-\mathrm{HM}}$ in IMs $(C Y P 2 D 6 * 1 / * 10, C Y P 2 D 6 * 1 / * 4$ or 
CYP2D6*1/*5, CYP $2 D 6 * 10 / * 10$ and $C Y P 2 D 6 * 5 / * 10$ ) were estimated to be lower than that in EM $\left(C Y P 2 D 6^{*} 1 / * 1\right)$. Both for tolterodine and 5-HM, the relative enzyme activities to $C Y P 2 D 6 * 1 / * 1$ in $C Y P 2 D 6 * 1 / * 10, C Y P 2 D 6 * 1 / * 4$ or $C Y P 2 D 6 * 1 / * 5$ and CYP2D6*10/*10 were estimated as approximately $70 \%, 50 \%$ and $40 \%$ of CYP2D6*1/*1, respectively (Table 3 ). Individual relative activity in 2 subjects of CYP2D6*5/*10 were less than $30 \%$.

Simulation of the exposures of unbound tolterodine, 5-HM and active moiety with changing intrinsic clearance of CYP2D6

Once CLint of EM $\left(C Y P 2 D 6^{*} 1 / * 1\right)$ and PM $(C Y P 2 D 6 * 4 / 4)$ are determined, the AUC

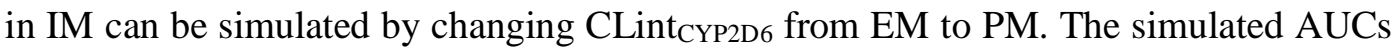
of unbound tolterodine, unbound 5-HM and active moiety with changing CLint CYP2D6 are shown in Figure 4. The observed mean AUCs of each genotype in the present study

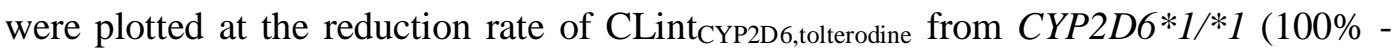
relative activity in Table 3).

In the simulation, tolterodine AUC continued to increase from the exposure in EM $(C Y P 2 D 6 * 1 / * 1)$ to the exposure in PM $(C Y P 2 D 6 * 4 / * 4)$ with decreasing CLint ${ }_{C Y P 2 D 6}$ (Figure 4). The exposure increased steeply from about $80 \%$ reduction in CLint CYP2D6. For 5-HM, from the level in EM, AUC increased to the peak with decreasing enzyme

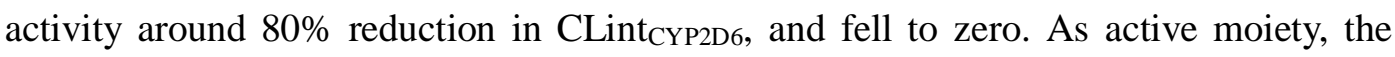
sum of unbound fraction of tolterodine and 5-HM, the exposure described a curve with

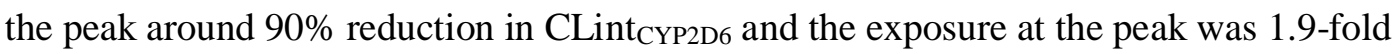
higher than EM. It was simulated that the exposures in EM and PM were almost comparable whereas those in IMs $(C Y P 2 D 6 * 1 / * 10, C Y P 2 D 6 * 1 / * 4$ or CYP2D6*1/*5, $C Y P 2 D 6 * 10 / * 10$ and $C Y P 2 D 6 * 5 / * 10)$ who had reduced enzyme activity were higher than the exposures in EM and PM. The simulated AUC in IMs were well matched with the observed IM values in the present study and the highest simulated active moiety exposure was around the observed value of $C Y P 2 D 6 * 5 / * 10$. 
DMD \#33407

We used the reported mean values of $\mathrm{fu}_{\text {tolterodine }}$ and $\mathrm{fu}_{5-\mathrm{HM}}$ for this simulation (see Method section). When $\mathrm{fu}_{\text {tolterodine }}$ and $\mathrm{fu}_{5-\mathrm{HM}}$ are changed from minimum ( $\mathrm{fu}_{\text {tolterodine: }}$ 0.016 and $\left.\mathrm{fu}_{5-\mathrm{HM}}: 0.21\right)$ to maximum (0.063 and 0.52 , respectively) in the present study, the maximum increase of the active moiety from EM (2.3-fold) was similar to the result of mean fut $\mathrm{u}_{\text {tolterodine }}$ and $\mathrm{fu}_{5-\mathrm{HM}}(1.9$-fold $)$. 


\section{Discussion}

This is the first report of clinical study to demonstrate the impact of $C Y P 2 D 6^{*} 10$ allele on tolterodine and 5-HM exposures. We also provided the first example of which IM shows higher exposure to pharmacological active moiety than EM and PM.

In the present study, we found spontaneous incidences of $C Y P 2 D 6 * 10$ in Asians $(40 \%)$ similar to previous reports (Bradford, 2002; Ozawa et al., 2004; Ingelman-Sundberg, 2005; Bernard et al., 2006). Some deficient or reduced mutations of CYP2D6 other than $C Y P 2 D 6 * 10$ such as $C Y P 2 D 6 * 14, C Y P 2 D 6 * 21, C Y P 2 D 6 * 41$, had been reported in Asian populations (Yamazaki et al., 2003; Kubo et al., 2007; Sakuyama et al., 2008). In our study, one Asian subject classified as $C Y P 2 D 6^{*} 1 / * 1$ showed higher serum concentrations of tolterodine and lower concentration of 5-HM. There is a possibility that this subject had one of these mutations. The existence of such reduced unidentified mutations in $C Y P 2 D 6^{*} 1 / * 1$ might make it more difficult to detect the differences in exposures between $C Y P 2 D 6^{*} 1 / * 1$ and IMs $\left(C Y P 2 D 6^{*} 1 / * 10, C Y P 2 D 6^{*} 1 / * 4\right.$ or CYP2D6*1/*5, CYP2D6*10/*10 and CYP2D6*5/*10). Nevertheless, in the present study, a significant difference between $C Y P 2 D 6 * 1 / * 1$ and $C Y P 2 D 6 * 10 / * 10$ was observed.

The tolterodine and 5-HM pharmacokinetic parameters in CYP2D6*1/*1 and homozygous of non-functional allele $(C Y P 2 D 6 * 4 / * 4)$ were comparable with those for EM and PM previously reported (Olsson and Szamosi, 2001). As a result, the active moiety exposures were almost the same between $C Y P 2 D 6 * 1 / * 1$ and $C Y P 2 D 6 * 4 / * 4$ in the present study (24 $\mathrm{nM} \mathrm{h}$ in $C Y P 2 D 6^{*} 1 / * 1$ and $30 \mathrm{nM} \mathrm{h}$ in $\left.C Y P 2 D 6 * 4 / 4\right)$, as previously reported.

As expected from enzyme activity reduced by $C Y P 2 D 6 * 10$ in vitro studies (Yokota et al., 1993; Johansson et al., 1994), the exposure of tolterodine increased in the order of $C Y P 2 D 6 * 1 / * 1<C Y P 2 D 6 * 1 / * 10<C Y P 2 D 6 * 1 / * 4$ or $C Y P 2 D 6 * 1 / 5<C Y P 2 D 6 * 10 / * 10$ 
$<C Y P 2 D 6 * 5 / * 10<C Y P 2 D 6 * 4 / * 4$. It was expected that the order of 5-HM exposure would be reversed. However, 5-HM AUC increased in the same order as tolterodine AUC except for $C Y P 2 D 6 * 4 / * 4$.

The active metabolite 5-HM is the metabolite of tolterodine by CYP2D6 and 5-HM itself is also metabolized by CYP2D6. When the activity of CYP2D6 reduces, 5-HM exposure may decrease due to decreasing the amount of 5-HM biotransformed from tolterodine (reduction of the exposure), whereas exposure of 5-HM may increase due to reduction of clearance for 5-HM (enhancement of the exposure) (Figure 5). The 5-HM exposure in subjects with reduced function allele depends on the balance of opposite directional effects, reduction and enhancement of 5-HM exposure.

With regard to the magnitude of enzyme activity reduction, the relative enzyme activity to $C Y P 2 D 6^{*} 1 / * 1$ in each genotype was estimated from the data of the present study. Those in $C Y P 2 D 6 * 1 / * 10, C Y P 2 D 6 * 1 / * 4$ or $C Y P 2 D 6 * 1 / * 5$ and $C Y P 2 D 6 * 10 / * 10$ were approximately $70 \%, 50 \%$ and $40 \%$ of $C Y P 2 D 6^{*} 1 / * 1$, respectively, both for tolterodine and 5-HM. Though Shen et al. reported that the extent of decrease in enzyme activity of $C Y P 2 D 6 * 10$ in comparison with $C Y P 2 D 6 * 1$ was different among various substrates in vitro (Shen et al., 2007), at least for tolterodine and 5-HM, it was expected that the relative enzyme activity of $C Y P 2 D 6 * 10$ compare to $C Y P 2 D 6 * 1$ were the same.

In the simulation with the estimated CLint ${ }_{\mathrm{CY} 2 \mathrm{D} 6}$, in contrast with continuous increase of tolterodine exposure with decreasing enzyme activity, the 5-HM exposure described a curve with a peak (Figure 4). It was considered that the effect of enzyme activity reduction on elimination of 5-HM (enhancement of the exposure) was dominant in the area from mild to moderate reduction, and the reducing effect on production of 5-HM (reduction of the exposure) became dominant when the reduction was excessive. From our simulation results, the peak of 5-HM exposure after administration of tolterodine

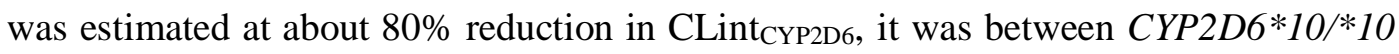
and $C Y P 2 D 6 * 5 / * 10$ in the present study. When the enzyme activity reduction was mild 
to moderate, active moiety exposure increased with decreasing enzyme activity because both tolterodine and 5-HM increased with decreasing enzyme activity. When the enzyme activity reduction was excessive, the 5-HM exposure fell to zero, but active moiety exposure was still higher than that in $C Y P 2 D 6 * 1 / * 1$ due to compensation by steep increase of tolterodine. As a result, it was simulated that all IMs $\left(C Y P 2 D 6^{*} 1 / * 10\right.$, $C Y P 2 D 6 * 1 / * 4$ or $C Y P 2 D 6 * 1 / * 5, C Y P 2 D 6 * 10 / * 10$ and $C Y P 2 D 6 * 5 / * 10)$ had higher active moiety exposure than those in EM $(C Y P 2 D 6 * 1 / * 1)$ and PM $(C Y P 2 D 6 * 4 / * 4)$. This simulation result was well matched with observed phenomenon in the present study and the highest simulated active moiety exposure was around the observed value of $C Y P 2 D 6 * 5 / * 10$.

With regard to the Cmax of 5-HM, no differences were observed among genotypes although AUCs in IMs were higher than EM. This is possibly explained as follows: The formulation was sustained release formulation and the releasing of tolterodine could be considered as infusion. The 5-HM Cmax is determined by this infusion rate and clearances for tolterodine and 5-HM which are influenced by genotype. On the other hand, the 5-HM AUC is determined by only the clearances. Under this circumstance, it is possible that Cmaxs were observed the same but AUCs were different among genotypes.

In the present study, as a result of a 3-fold increase of tolterodine exposure and 1.5-fold increase of 5-HM exposure, active moiety exposure which is the sum of unbound fraction of tolterodine and 5-HM was 1.8 fold in subjects with $C Y P 2 D 6 * 10 / * 10$ than $C Y P 2 D 6^{*} 1 / * 1$ and this was also higher than $C Y P 2 D 6 * 4 / * 4$ (Figure 3 and Table 2). In the simulation, the highest simulated active moiety exposure was around the observed value of $C Y P 2 D 6 * 5 / * 10$ and it was 1.9 -fold higher than EM $(C Y P 2 D 6 * 1 / * 1)$. Although such difference in exposure could cause the difference of optimal doses between Western and Asian countries, the approved Asian dosage and administration is the same as the US/EU, a once a daily dose of $4 \mathrm{mg}$ tolterodine PR capsule 
DMD \#33407

(http://www.accessdata.fda.gov/drugsatfda_docs/label/2010/021228s015lbl.pdf, http://www.info.pmda.go.jp/go/pack/2590012M1021_1_05/, ; Clemett and Jarvis, 2001). For tolterodine case, difference of active moiety exposure between the ethnicities is presumably within the range of the safety and efficacy margins.

When only a parent compound has a significant pharmacological effect, the order of exposure to pharmacological active moiety is $\mathrm{PM}>\mathrm{IM}>\mathrm{EM}$ because the exposure continues to increase with decreasing enzyme activity. However, if a parent drug and its metabolite have a pharmacological effect and both of them are predominantly metabolized by CYP2D6, there is a possibility that IM has the highest active moiety exposure. In such case, Asians who predominantly possesses reduced function alleles has possibly higher exposure of the pharmacological active moiety than the populations who do not, in general, posses reduced function alleles, such as Caucasians. This should be taken into consideration for optimal dose selection in global drug development. 
DMD \#33407

\section{References}

Bernard S, Neville KA, Nguyen AT and Flockhart DA (2006) Interethnic differences in genetic polymorphisms of CYP2D6 in the U.S. population: clinical implications. Oncologist 11:126-135.

Bradford LD (2002) CYP2D6 allele frequency in European Caucasians, Asians, Africans and their descendants. Pharmacogenomics 3:229-243.

Brynne N, Dalen P, Alvan G, Bertilsson L and Gabrielsson J (1998) Influence of CYP2D6 polymorphism on the pharmacokinetics and pharmacodynamic of tolterodine. Clin Pharmacol Ther 63:529-539.

Clemett D and Jarvis B (2001) Tolterodine: a review of its use in the treatment of overactive bladder. Drugs Aging 18:277-304.

Ingelman-Sundberg M (2005) Genetic polymorphisms of cytochrome P450 2D6 (CYP2D6): clinical consequences, evolutionary aspects and functional diversity. Pharmacogenomics J5:6-13.

Ito $\mathrm{K}$ and Houston JB (2004) Comparison of the use of liver models for predicting drug clearance using in vitro kinetic data from hepatic microsomes and isolated hepatocytes. Pharm Res 21:785-792.

Johansson I, Oscarson M, Yue QY, Bertilsson L, Sjoqvist F and Ingelman-Sundberg M (1994) Genetic analysis of the Chinese cytochrome P4502D locus: characterization of variant CYP2D6 genes present in subjects with diminished capacity for debrisoquine hydroxylation. Mol Pharmacol 46:452-459.

Kato M, Chiba K, Hisaka A, Ishigami M, Kayama M, Mizuno N, Nagata Y, Takakuwa S, Tsukamoto Y, Ueda K, Kusuhara H, Ito K and Sugiyama Y (2003) The intestinal first-pass metabolism of substrates of CYP3A4 and P-glycoprotein-quantitative analysis based on information from the literature. Drug Metab Pharmacokinet 18:365-372.

Kubo M, Koue T, Maune H, Fukuda T and Azuma J (2007) Pharmacokinetics of aripiprazole, a new antipsychotic, following oral dosing in healthy adult Japanese volunteers: influence of CYP2D6 polymorphism. Drug Metab Pharmacokinet 22:358-366.

Larsson G, Hallen B and Nilvebrant L (1999) Tolterodine in the treatment of overactive bladder: analysis of the pooled phase II efficacy and safety data. Urology 53:990-998.

Malhotra B, Guan Z, Wood N and Gandelman K (2008) Pharmacokinetic profile of fesoterodine. Int J Clin Pharmacol Ther 46:556-563.

Nilvebrant L (2000) The mechanism of action of tolterodine. Rev Contemp

Pharmacotherapy 11:13-27.

Olsson B and Szamosi J (2001) Multiple dose pharmacokinetics of a new once daily extended release tolterodine formulation versus immediate release tolterodine. Clin Pharmacokinet 40:227-235.

Ozawa S, Soyama A, Saeki M, Fukushima-Uesaka H, Itoda M, Koyano S, Sai K, Ohno Y, Saito Y and Sawada J (2004) Ethnic differences in genetic polymorphisms of CYP2D6, CYP2C19, CYP3As and MDR1/ABCB1. Drug Metab Pharmacokinet 19:83-95.

Pahlman I and Gozzi P (1999) Serum protein binding of tolterodine and its major metabolites in humans and several animal species. Biopharm Drug Dispos 20:91-99.

Postlind H, DanielsonA, Lindgren A and Andersson SH (1998) Tolterodine, a new muscarinic receptor antagonist, is metabolized by cytochromes P450 2D6 and 3A in human liver microsomes. Drug Metab Dispos 26:289-293.

Sakuyama K, Sasaki T, Ujiie S, Obata K, Mizugaki M, Ishikawa M and Hiratsuka M (2008) Functional characterization of 17 CYP2D6 allelic variants (CYP2D6.2, 10, 14A-B, 18, 27, 36, 39, 47-51, 53-55, and 57). Drug Metab Dispos 36:2460-2467.

Shen H, He MM, Liu H, Wrighton SA, Wang L, Guo B and Li C (2007) Comparative metabolic capabilities and inhibitory profiles of CYP2D6.1, CYP2D6.10, and CYP2D6.17. Drug Metab Dispos 35:1292-1300.

Van Kerrebroeck P, Kreder K, Jonas U, Zinner N and Wein A (2001) Tolterodine once-daily: 
DMD \#33407

superior efficacy and tolerability in the treatment of the overactive bladder. Urology 57:414-421.

Yamazaki H, Kiyotani K, Tsubuko S, Matsunaga M, Fujieda M, Saito T, Miura J, Kobayashi S and Kamataki T (2003) Two novel haplotypes of CYP2D6 gene in a Japanese population. Drug Metab Pharmacokinet 18:269-271.

Yokota H, Tamura S, Furuya H, Kimura S, Watanabe M, Kanazawa I, Kondo I and Gonzalez FJ (1993) Evidence for a new variant CYP2D6 allele CYP2D6J in a Japanese population associated with lower in vivo rates of sparteine metabolism. Pharmacogenetics 3:256-263.

Zhou SF (2009) Polymorphism of human cytochrome P450 2D6 and its clinical significance: Part I. Clin Pharmacokinet 48:689-723. 
DMD \#33407

\section{Footnotes}

\section{Address correspondence to:}

Masayo Oishi, Pfizer Japan Inc, Development Japan, Clinical Pharmacology, Shinjuku

Bunka Quint Bldg., 3-22-7, Yoyogi, Shibuya-ku, Tokyo, 151-8589, Japan 
DMD \#33407

\section{Legend for figures}

Figure 1 Dose normalized Cmax and AUC of tolterodine in each genotype. Left panel shows Cmax and right panel shows $\mathrm{AUC}_{0-24}$. The box edges show 25th and 75th percentiles. The whiskers extend from each box edge to the furthest data within a distance of 1.5 interquantile ranges from 25 th and 75 th percentiles. The open circles outside the whiskers represent outliers. Significantly higher than $C Y P 2 D 6^{*} 11^{*} 1 \quad(*)$, and higher than $C Y P 2 D 6^{*} 1 / * 10(\dagger)$, using Bonferroni's post hoc test $(\mathrm{P}<0.05)$.

Figure 2 Dose normalized Cmax and AUC of 5-HM in each genotype. Left panel shows Cmax and right panel shows $\mathrm{AUC}_{0-24}$. The box edges show 25th and 75th percentiles. The whiskers extend from each box edge to the furthest data within a distance of 1.5 interquantile ranges from 25 th and 75 th percentiles. The open circles outside the whiskers represent outliers. Significantly higher than $C Y P 2 D 6 * 1 / * 1(*)$, and higher than $C Y P 2 D 6 * 1 / * 10(\dagger)$, using Bonferroni's post hoc test $(\mathrm{P}<0.05)$.

Figure 3 Dose normalized Cmax and AUC of active moiety in each genotype. Left panel shows Cmax and right panel shows $\mathrm{AUC}_{0-24}$. The box edges show 25th and 75th percentiles. The whiskers extend from each box edge to the furthest data within a distance of 1.5 interquantile ranges from 25 th and 75 th percentiles. The open circles outside the whiskers represent outliers. Significantly higher than $C Y P 2 D 6 * 1 / * 1(*)$, and higher than $C Y P 2 D 6 * 1 / * 10$ $(\dagger)$, using Bonferroni's post hoc test $(\mathrm{P}<0.05)$.

Figure 4 Relationships between AUCs of unbound fraction of tolterodine (green), 5-HM (blue) and active moiety (red) after tolterodine administration and reduction

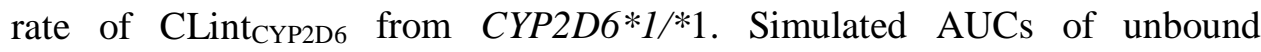
tolterodine, unbound 5-HM and active moiety are shown in green, blue and red solid line, respectively. Mean values of observed AUC of unbound tolterodine, unbound 5-HM and active moiety in the present study in $C Y P 2 D 6 * 1 / * 1(\mathbf{\square})$, CYP2D6*1/*10 (•), CYP $2 D 6 * 1 / * 4$ or $* 1 / * 5(\bullet), C Y P 2 D 6 * 10 / * 10(\mathbf{\Delta})$ are

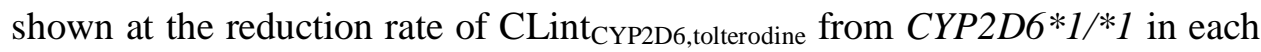
genotype (100\% - relative activity in Table 3$)$ as closed symbols with standard deviation. Individual values of $C Y P 2 D 6 * 5 / * 10$ and $C Y P 2 D 6 * 4 / 4$ are shown as open triangles and open inverted triangles, respectively.

Figure 5 The relationships between change of CYP2D6 enzyme activity and exposure of tolterodine and 5-HM among EM, IM and PM. Square boxes are the compartments for tolterodine and 5-HM. Shaded areas in the boxes are the 
amount of each compounds in the compartment. Width of allows are correspondent to the contribution ratio of each clearance of metabolic/ excretion pathway. Tolterodine exposure increases with decreasing CYP2D6 enzyme activity. 5-HM exposure in IM who has reduced CYP2D6 enzyme activity is determined by the balance between opposite directional effects, i.e. reduction and enhancement of the exposure. IM can have higher 5-HM exposure than EM when the enhancement effect is dominant. As a result, IM has the highest exposure of active moiety, sum of unbound tolterodine and 5-HM. 
DMD \#33407

Table 1 Demographics of subjects in each genotype

\begin{tabular}{ccccc}
\hline Genotype & $\begin{array}{c}\text { Gender } \\
\text { male }\end{array}$ & $\begin{array}{c}\text { Age } \\
(\text { years })\end{array}$ & $\begin{array}{c}\text { Height } \\
(\mathrm{cm})\end{array}$ & $\begin{array}{c}\text { Weight } \\
(\mathrm{kg})\end{array}$ \\
\hline$* 1 / * 1$ & $20(44.4 \%)$ & $32.9(10.1)$ & $166.7(8.9)$ & $62.1(8.1)$ \\
$(\mathrm{n}=45)$ & $6(19.4 \%)$ & $33.3(9.6)$ & $162.8(8.7)$ & $58.0(7.6)$ \\
\hline $\begin{array}{c}* 1 / 10 \\
(\mathrm{n}=31)\end{array}$ & $3(20.0 \%)$ & $36.3(10.2)$ & $162.8(8.0)$ & $56.2(5.7)$ \\
\hline$* 1 / * 4$ or $* 1 / * 5$ \\
$(\mathrm{n}=15)$
\end{tabular}

Data are presented as mean (standard deviation (SD)) except for gender. If number of subject is less than 2, individual values are shown instead of descriptive summary. 
DMD \#33407

Table 2 Dose normalized Cmax and AUC of tolterodine, 5-HM and active moiety in each genotype

\begin{tabular}{|c|c|c|c|c|c|c|}
\hline \multirow[b]{2}{*}{ Genotype } & \multicolumn{2}{|c|}{ Tolterodine } & \multicolumn{2}{|c|}{ 5-HM } & \multicolumn{2}{|c|}{ Active moiety } \\
\hline & $\begin{array}{c}\text { Cmax } \\
(\mathrm{ng} / \mathrm{mL})\end{array}$ & $\begin{array}{c}\mathrm{AUC}_{0-24} \\
(\mathrm{ng} \mathrm{h} / \mathrm{mL})\end{array}$ & $\begin{array}{c}\mathrm{Cmax} \\
(\mathrm{ng} / \mathrm{mL})\end{array}$ & $\begin{array}{c}\mathrm{AUC}_{0-24} \\
(\mathrm{ng} \mathrm{h} / \mathrm{mL})\end{array}$ & $\begin{array}{l}\text { Cmax } \\
(\mathrm{nM})\end{array}$ & $\begin{array}{l}\mathrm{AUC}_{0-24} \\
(\mathrm{nM} \mathrm{h})\end{array}$ \\
\hline $\begin{array}{c}* 1 / * 1 \\
(\mathrm{n}=45)\end{array}$ & $\begin{array}{c}1.65(2.66) \\
{[0.85-2.45]}\end{array}$ & $\begin{array}{l}17.05(33.66) \\
{[6.93-27.16]}\end{array}$ & $\begin{array}{c}2.09(1.24) \\
{[1.72-2.47]}\end{array}$ & $\begin{array}{c}21.39(10.44) \\
{[18.26-24.53]}\end{array}$ & $\begin{array}{c}2.35(1.01) \\
{[2.04-2.65]}\end{array}$ & $\begin{array}{c}24.23(8.60) \\
{[21.65-26.82]}\end{array}$ \\
\hline $\begin{array}{l}* 1 / * 10 \\
(\mathrm{n}=31)\end{array}$ & $\begin{array}{c}1.64(0.92) \\
{[1.30-1.98]}\end{array}$ & $\begin{array}{c}17.18(8.80) \\
{[13.95-20.40]}\end{array}$ & $\begin{array}{c}2.11(0.84) \\
{[1.80-2.41]}\end{array}$ & $\begin{array}{c}24.18(7.79) \\
{[21.32-27.04]}\end{array}$ & $\begin{array}{c}2.74(1.10) \\
{[2.33-3.14]}\end{array}$ & $\begin{array}{l}31.39^{*}(10.73) \\
{[27.45-35.33]}\end{array}$ \\
\hline $\begin{array}{c}* 1 / * 4 \text { or } * 1 / * 5 \\
(\mathrm{n}=15)\end{array}$ & $\begin{array}{c}3.18(2.08) \\
{[2.03-4.33]}\end{array}$ & $\begin{array}{c}33.63(29.04) \\
{[17.54-49.71]}\end{array}$ & $\begin{array}{c}2.28(1.05) \\
{[1.70-2.85]}\end{array}$ & $\begin{array}{c}26.70(7.50) \\
{[22.54-30.85]}\end{array}$ & $\begin{array}{c}3.02(1.24) \\
{[2.33-3.71]}\end{array}$ & $\begin{array}{c}35.40^{*}(9.55) \\
{[30.11-40.70]}\end{array}$ \\
\hline $\begin{array}{r}* 10 / * 10 \\
(\mathrm{n}=13)\end{array}$ & $\begin{array}{l}4.31^{*, \dagger}(2.87) \\
{[2.58-6.04]}\end{array}$ & $\begin{array}{c}51.83^{*}, \dagger(36.26) \\
{[29.92-73.74]}\end{array}$ & $\begin{array}{c}2.33(0.87) \\
{[1.80-2.85]}\end{array}$ & $\begin{array}{l}31.36^{*}(10.57) \\
{[24.97-37.75]}\end{array}$ & $\begin{array}{l}3.35^{*}(1.51) \\
{[2.44-4.26]}\end{array}$ & $\begin{array}{l}44.23^{* \dagger}(18.36) \\
{[33.14-55.33]}\end{array}$ \\
\hline $\begin{array}{r}* 5 / * 10 \\
(\mathrm{n}=2)\end{array}$ & $6.06,6.34$ & $79.04,87.09$ & $1.89,2.25$ & $26.84,32.24$ & $2.89,3.84$ & $40.19,54.92$ \\
\hline $\begin{array}{l}* 4 / * 4 \\
(\mathrm{n}=2)\end{array}$ & $17.82,18.84$ & $346.10,358.94$ & NA & NA & $1.52,1.60$ & $29.54,30.64$ \\
\hline
\end{tabular}

Data are presented as mean (SD) and [95\% confidence interval]. If number of subject is less than 2, individual values are shown instead of descriptive summary. NA: not applicable.

Significantly higher than $C Y P 2 D 6 * 1 / * 1(*)$, and higher than $C Y P 2 D 6 * 1 / * 10(\dagger)$, using Bonferroni's post hoc test $(\mathrm{P}<0.05)$. 
DMD \#33407

Table 3 Estimated intrinsic clearances of CYP2D6 for tolterodine and for 5-HM and the relative enzyme activity to CYP2D6*1/*1 in each genotype

\begin{tabular}{|c|c|c|c|c|}
\hline \multirow[b]{2}{*}{ Genotype } & \multicolumn{2}{|c|}{ Tolterodine } & \multicolumn{2}{|r|}{ 5-HM } \\
\hline & $\begin{array}{c}\text { CLint }_{\mathrm{CYP2D} 6 \text {, tolterodine }} \\
(\mathrm{L} / \mathrm{h})\end{array}$ & $\begin{array}{l}\text { Relative enzyme activity } \\
\qquad \%)\end{array}$ & $\begin{array}{c}\text { CLint }_{\text {CYP2D6, 5-HM }} \\
(\mathrm{L} / \mathrm{h})\end{array}$ & $\begin{array}{l}\text { Relative enzyme activity } \\
\qquad(\%)\end{array}$ \\
\hline $\begin{array}{l}* 1 / * 1 \\
(\mathrm{n}=45)\end{array}$ & 4441 (1479) & 100 & $131(55)$ & 100 \\
\hline $\begin{array}{l}* 1 / * 10 \\
(\mathrm{n}=31)\end{array}$ & 2898 (1136) & 65 & $89(59)$ & 68 \\
\hline $\begin{array}{c}* 1 / * 4 \text { or } * 1 / * 5 \\
\quad(\mathrm{n}=15)\end{array}$ & $2121(984)$ & 48 & $68(43)$ & 52 \\
\hline $\begin{array}{r}* 10 / * 10 \\
(\mathrm{n}=13)\end{array}$ & 1594 (1287) & 36 & $48(51)$ & 37 \\
\hline $\begin{array}{r}* 5 / * 10 \\
(\mathrm{n}=2)\end{array}$ & 435,729 & 10,16 & 0,33 & 0,25 \\
\hline
\end{tabular}

Data are presented as mean (SD). If number of subject is less than 2, individual values are shown instead of descriptive summary. 
Figure 1
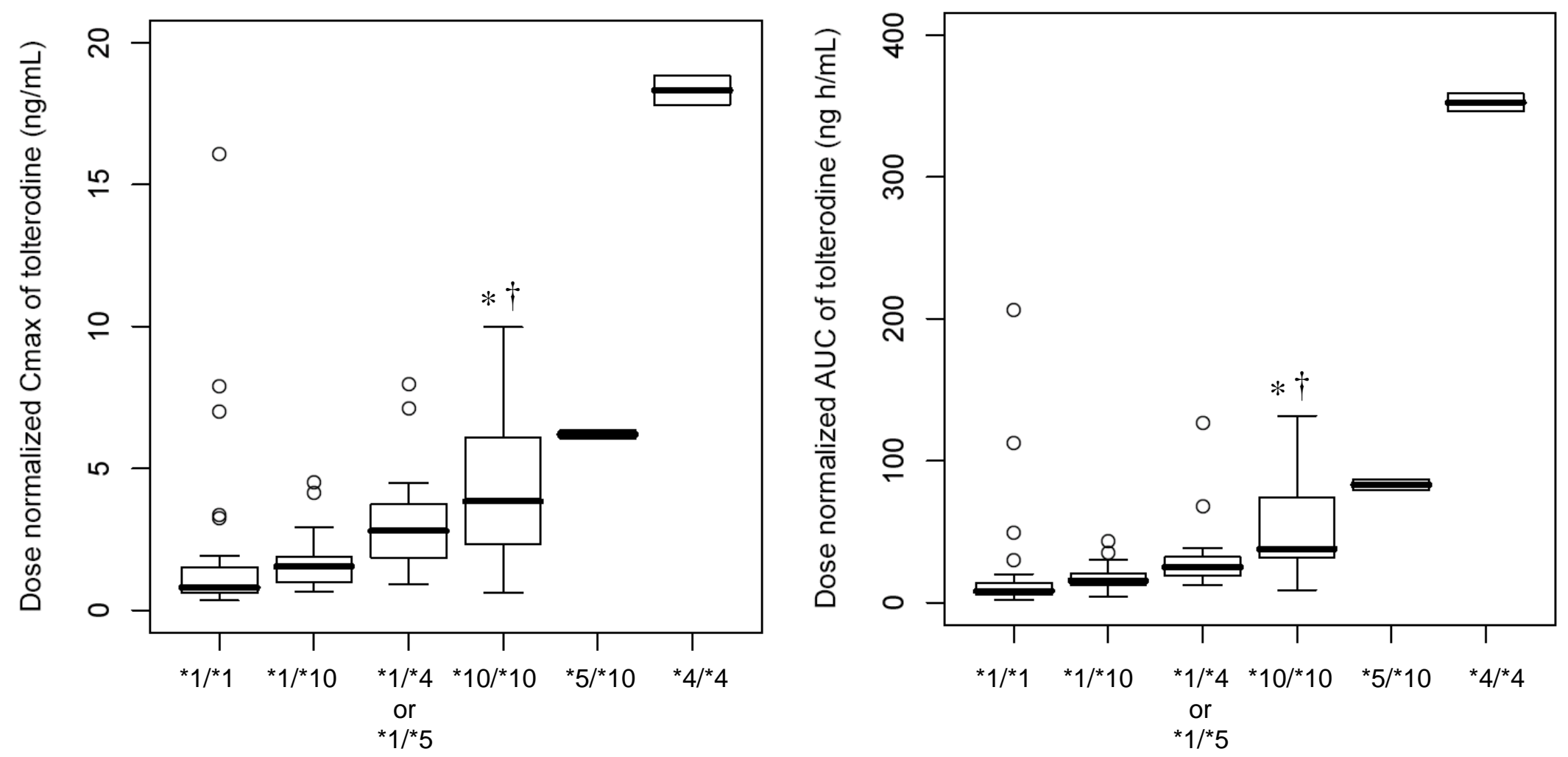
Figure 2
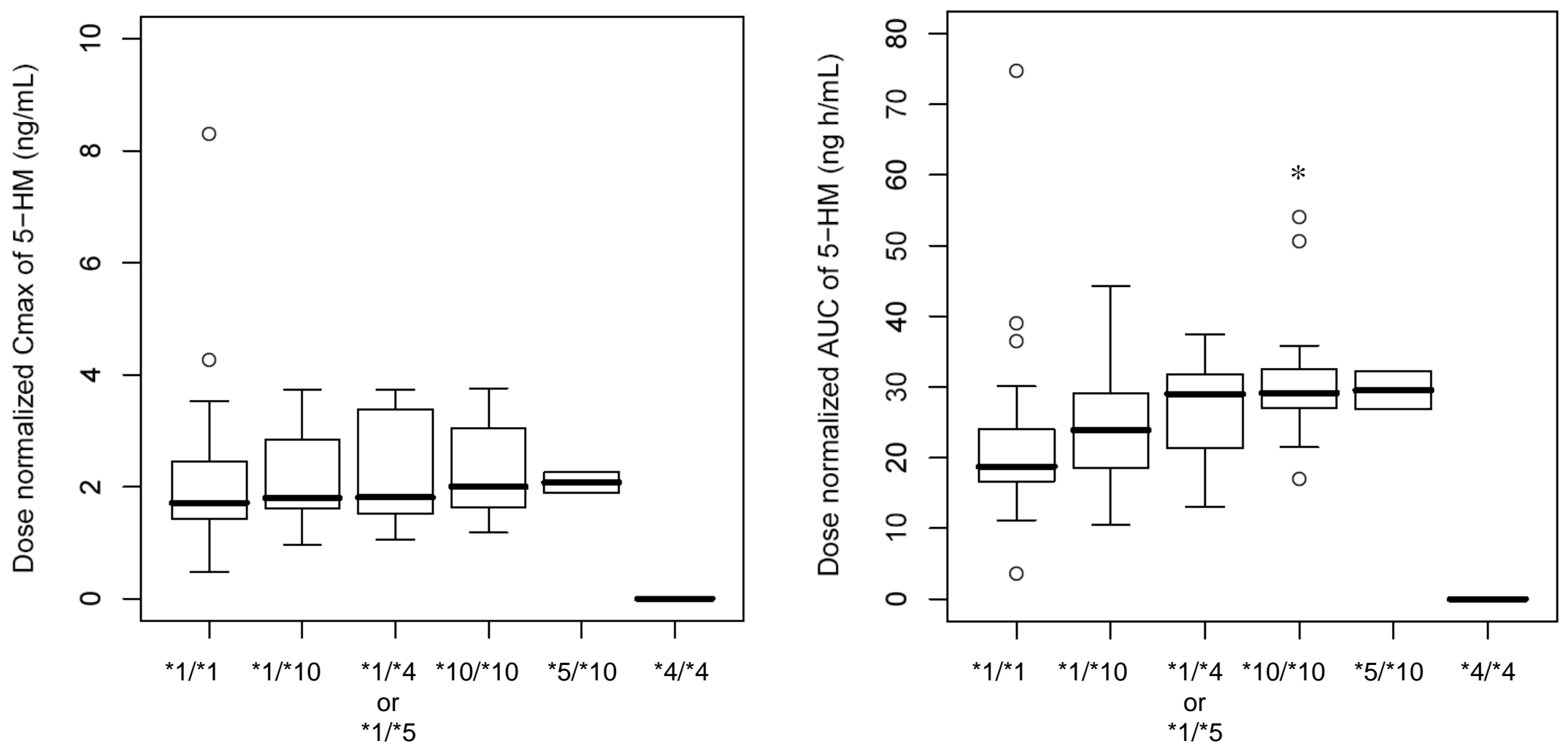
Figure 3
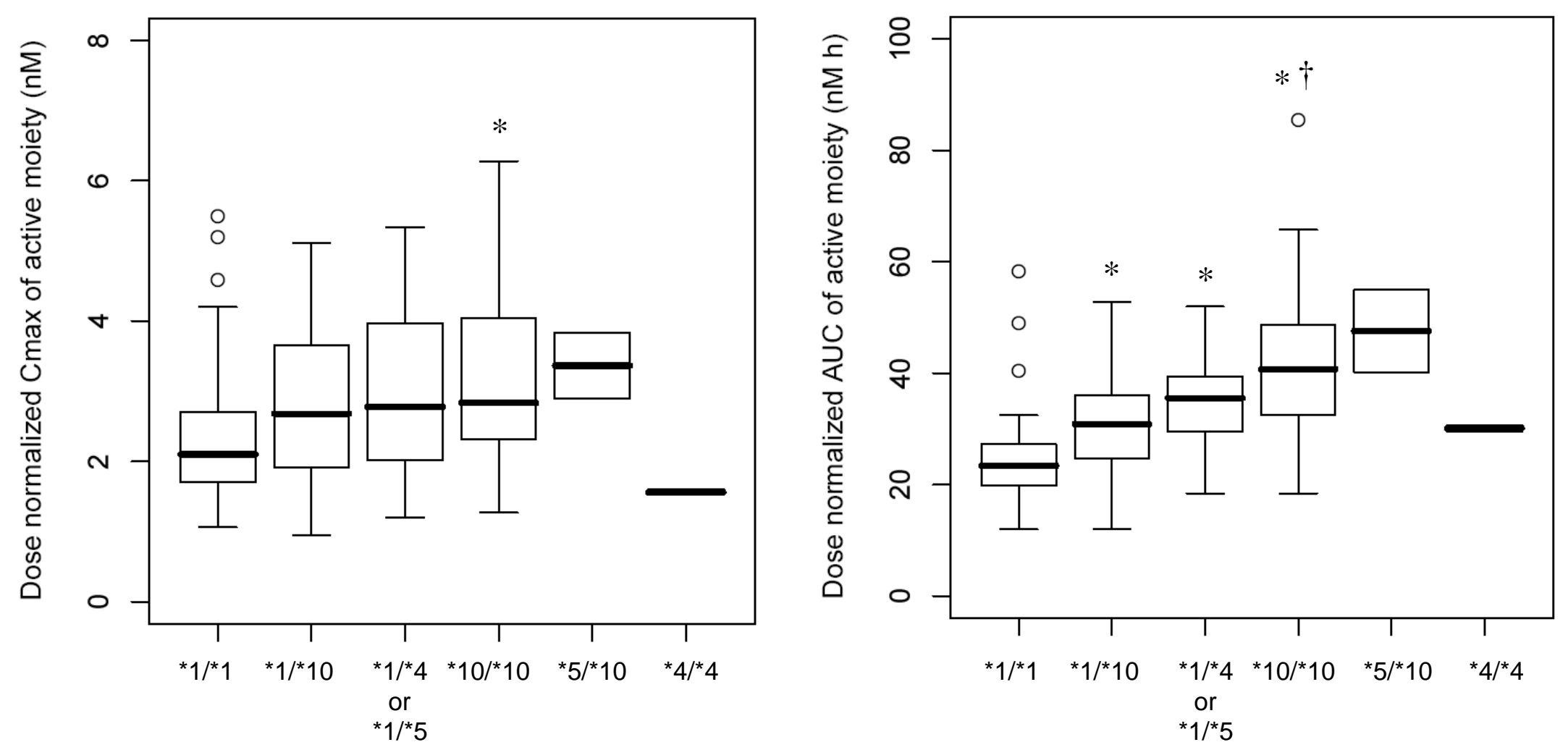
Figure 4

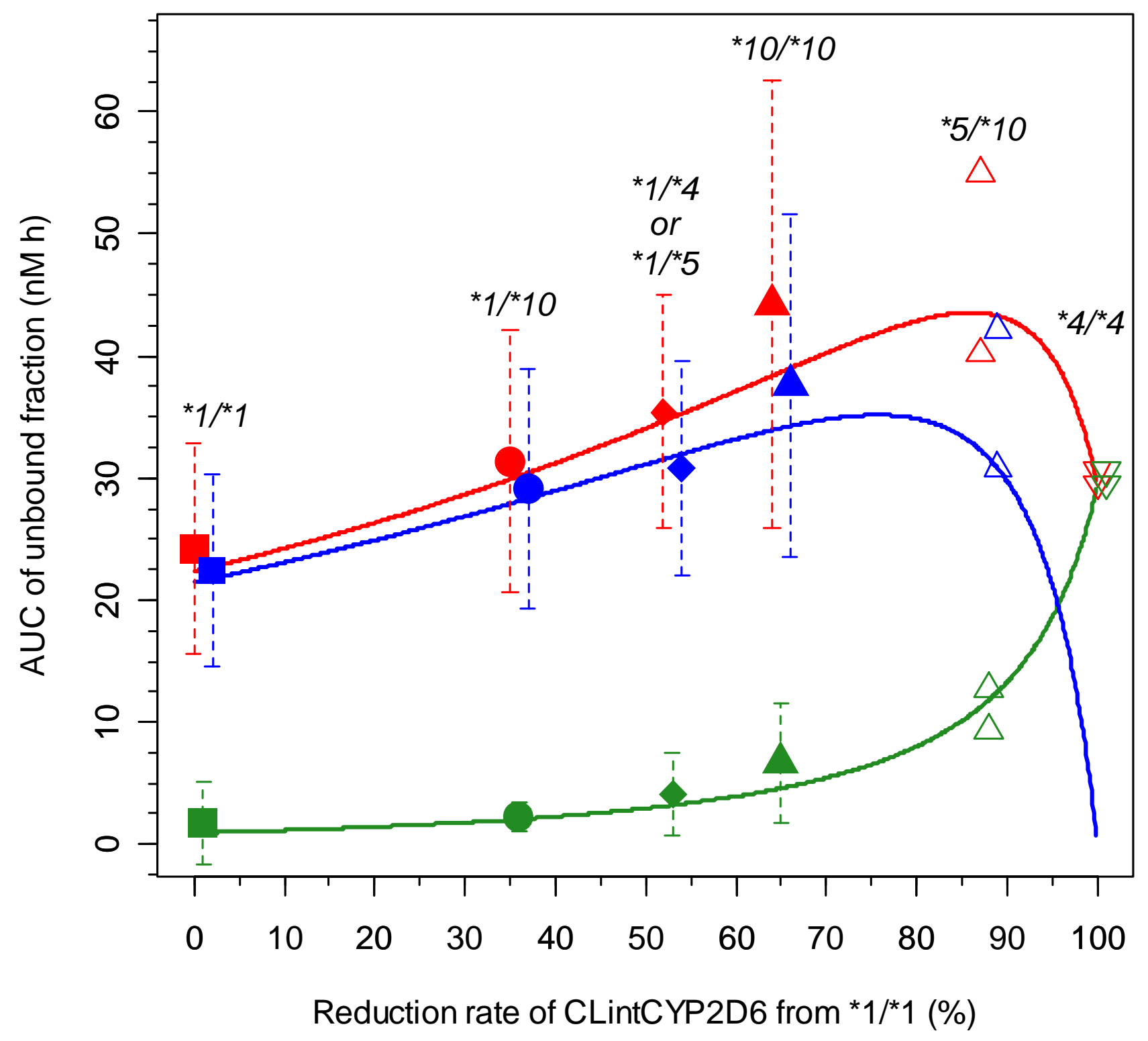


Figure 5

EM

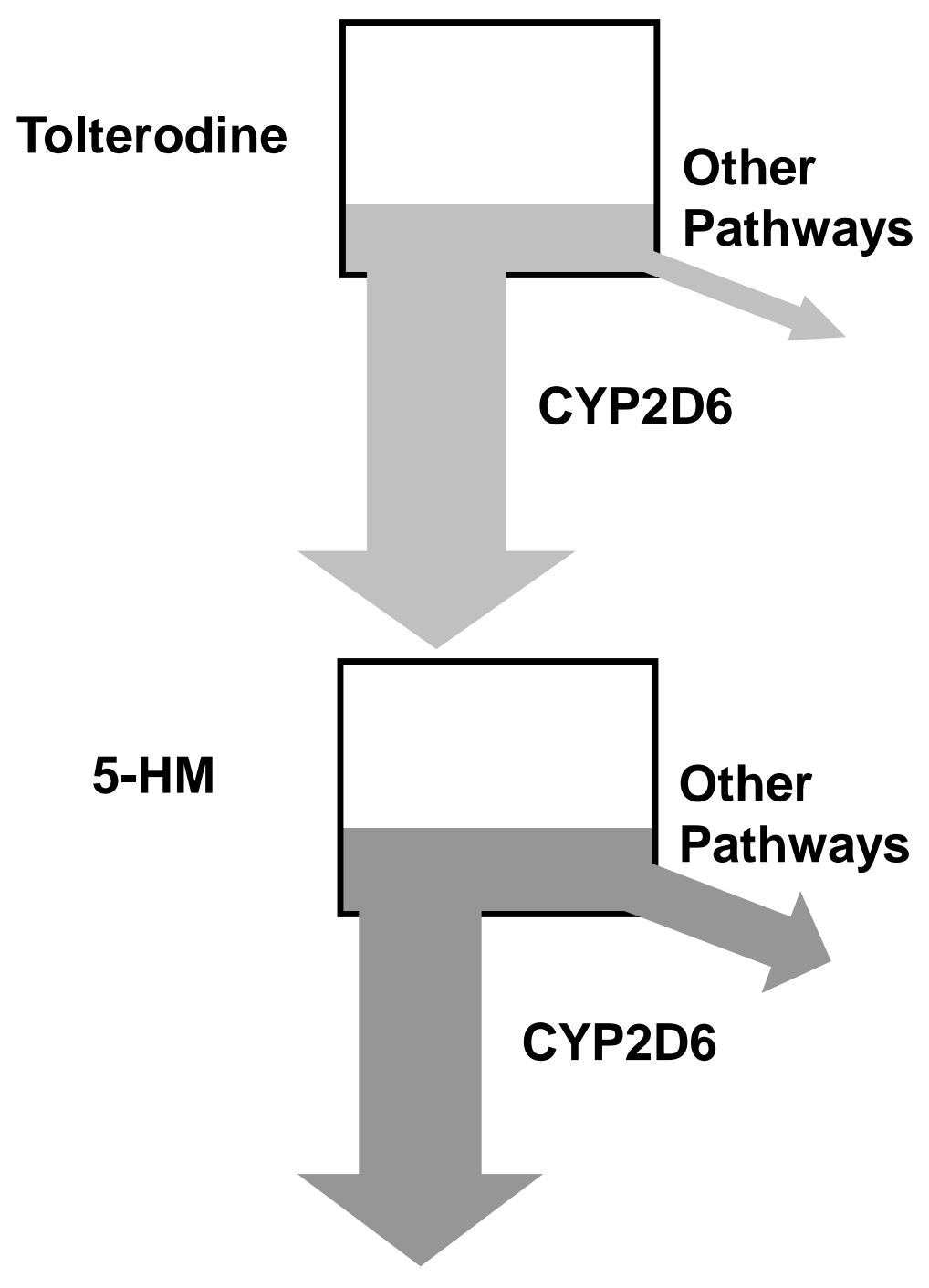

IM
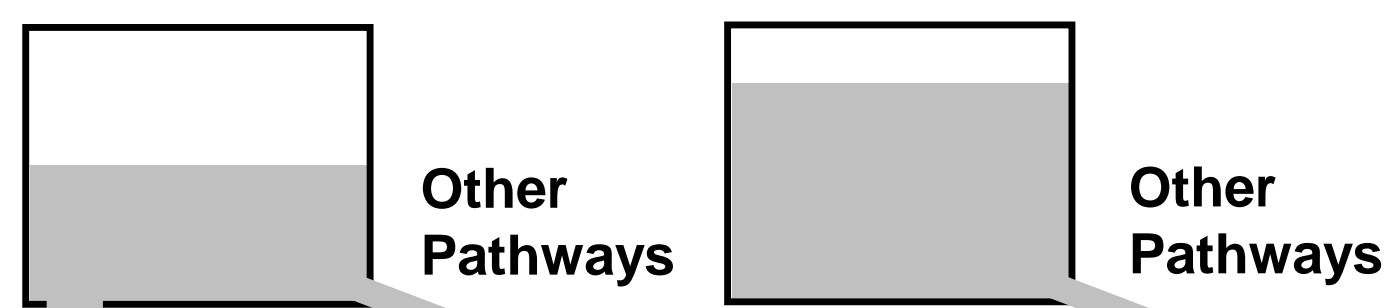

Enhancement of 5-HM

Exposure

Decreasing of 5-HM clearance 


\section{Appendix}

Appendix 1. Equations for the estimation of intrinsic clearance of CYP2D6 for tolterodine and the amount of tolterodine biotransformed to 5-HM in each CYP2D6 genotype (parallel tube model):

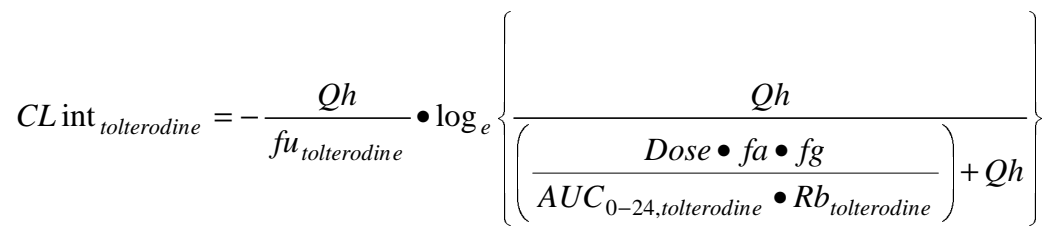

$C L$ int $_{C Y P 2 D 6, \text { tolterodine }}=C L$ int $_{\text {tolterodine }}-C L$ int $_{\text {other,tolterodine }}$

where Qh: hepatic blood flow rate, fu: fraction unbound, CLint: intrinsic clearance of each enzyme, fa: fraction absorbed, fg: intestinal availability. Subscript "other" means hepatic pathway other than CYP2D6 which is correspondent to hepatic pathway in PM. The following values were used for these estimations: Qh was calculated as $91.8 \mathrm{~L} / \mathrm{h}$ from $25 \mathrm{~mL} / \mathrm{min} / \mathrm{kg}$ (Kato et al., 2003) and $60 \mathrm{~kg}$ body weight, as approximately equal to mean body weight of the present study. The fu of tolterodine ( $\mathrm{fu}_{\text {tolterodine}}$ ) was calculated from individual AGP concentrations as described in the method section. Clearances were adjusted by blood to serum concentration ratio ( $\left.\mathrm{Rb}_{\text {tolterodine: }} 0.6\right)$. The median value of CLint tolterodine in $C Y P 2 D 6 * 4 / 44$ in the present study, $436 \mathrm{~L} / \mathrm{h}$ was used

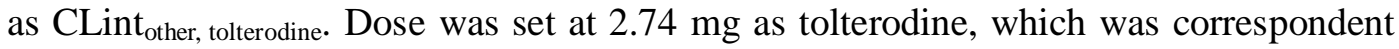
to $4 \mathrm{mg}$ of tolterodine tartrate (molecular weights for tolterodine and tolterodine tartrate are 325.5 and 475.6$)$.

The amount of 5-HM biotransformed from tolterodine (Dose ${ }_{5-\mathrm{HM}}$ ) was calculated as follows: 


$$
\begin{aligned}
& \text { Dose }_{5-H M}=\text { Dose } \bullet f a \bullet f g \bullet f m_{C Y P 2 D 6, \text { tolterodine }} \bullet \frac{M W_{\text {tolterodine }}}{M W_{5-H M}} \\
& f m_{C Y P 2 D 6, \text { tolterodine }}=\frac{C L \text { int }_{C Y P 2 D 6, \text { tolterodine }}}{C L \text { int }_{\text {tolterodine }}}
\end{aligned}
$$

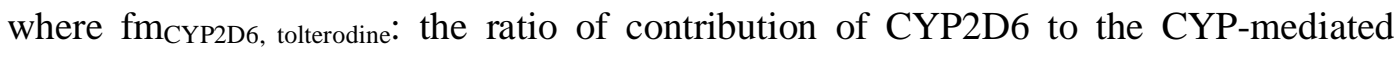
tolterodine clearance, MW: molecular weight, those of tolterodine and 5-HM were 325.5 and 341.5 , respectively.

Appendix 2. Equations for the estimation of intrinsic clearance of CYP2D6 for 5-HM in each CYP2D6 genotype (parallel tube model):

$$
\begin{aligned}
& C L \text { int }_{5-H M}=-\frac{Q h}{f u_{5-H M}} \bullet \log _{e}\left\{\frac{Q h+C L R_{5-H M}}{Q h+\left(\frac{D e_{5-H M}}{A U C_{0-24,5-H M} \bullet R b_{5-H M}}\right)}\right\}
\end{aligned}
$$

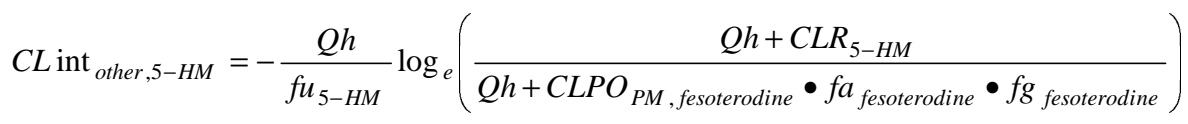

$$
\begin{aligned}
& C L \text { int }_{C Y P 2 D 6,5-H M}=C L \text { int }_{5-H M}-C L \text { int }_{\text {other }, 5-H M}
\end{aligned}
$$

where the fu of 5-HM ( $\left.\mathrm{fu}_{5-\mathrm{HM}}\right)$ was calculated from individual AGP concentrations as described in the method section. Renal clearance (CLR) was $16.4 \mathrm{~L} / \mathrm{h}$ (Malhotra et al., 2008). Clearances were adjusted by blood to serum concentration ratio ( $\left.\mathrm{Rb}_{\text {tolterodine: }} 0.8\right)$. The intrinsic clearance for 5-HM by the metabolic pathway other than CYP2D6 was calculated as $60.99 \mathrm{~L} / \mathrm{h}$ from oral clearance of 5-HM after administration of fesoterodine in PM (CLPO ${ }_{\mathrm{PM}}$, fesoterodine). This was calculated from AUC after $4 \mathrm{mg}$ dose of fesoterodine tablet, which was $44.5 \mathrm{ng} \mathrm{h} / \mathrm{mL}$ (Malhotra et al., 2008). The fa fesoterodine $\mathrm{X}$ $\mathrm{fg}_{\text {fesoterodine }}$ was calculated as 0.70 from reported bioavailability of 5-HM in EM $\left(\mathrm{fa}_{\text {fesoterodine }} \mathrm{x}\right.$ fg fesoterodine $\mathrm{x}$ fh-HM, EM) which was $42 \%$ as the ratio of 5-HM AUC after oral administration of fesoterodine tablet vs 5-HM IV dose in EM 
DMD \#33407

(http://www.emea.europa.eu/humandocs/Humans/EPAR/toviaz/toviaz.htm) and total clearance after administration of 5-HM IV dose in EM. Molecular weight of fesoterodine fumarate and 5-HM were 527.5 and 341.5 , respectively.

Appendix 3. Simulation of the exposures of unbound tolterodine, 5-HM and active moiety with changing intrinsic clearance of CYP2D6

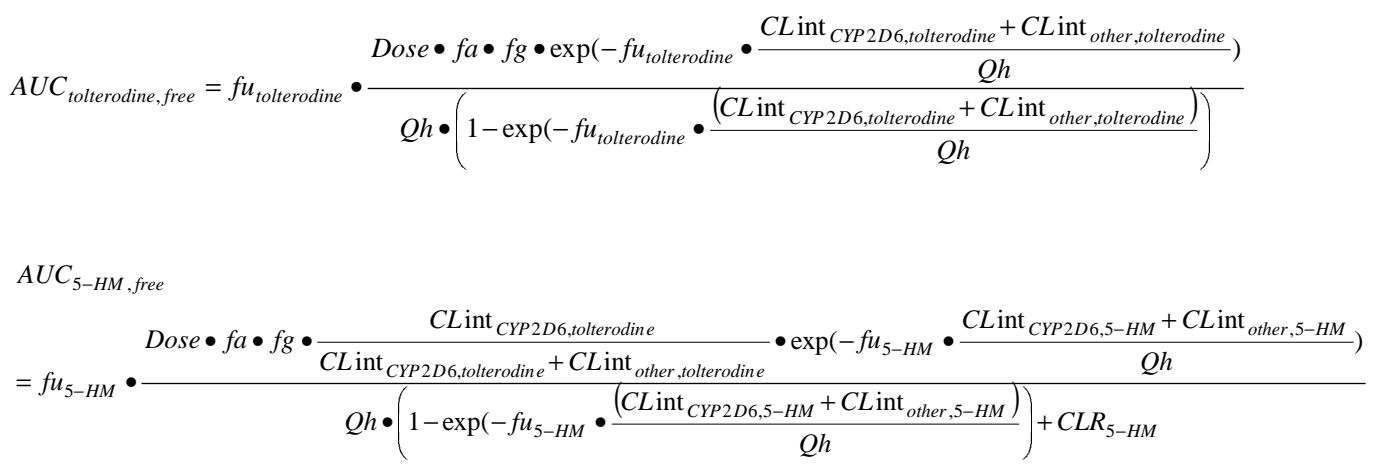

where CLint ${ }_{\mathrm{CPY} 2 \mathrm{D} 6 \text {,tolterodine }}$ and $\mathrm{CLint}_{\mathrm{CPY} 2 \mathrm{D} 6,5-\mathrm{HM}}$ were changed from no reduction which was the mean value of $C Y P 2 D 6 * 1 / * 1$ in the present study $(4441 \mathrm{~L} / \mathrm{h}$ for tolterodine and $130.6 \mathrm{~L} / \mathrm{h}$ for $5-\mathrm{HM}$, respectively) to $100 \%$ reduction equaled to the condition in PM. For all other parameters, the same values in Appendix 1 and 2 were used for the simulation. Active moiety exposure was calculated as the sum of molar AUCs of unbound tolterodine and 5-HM. 